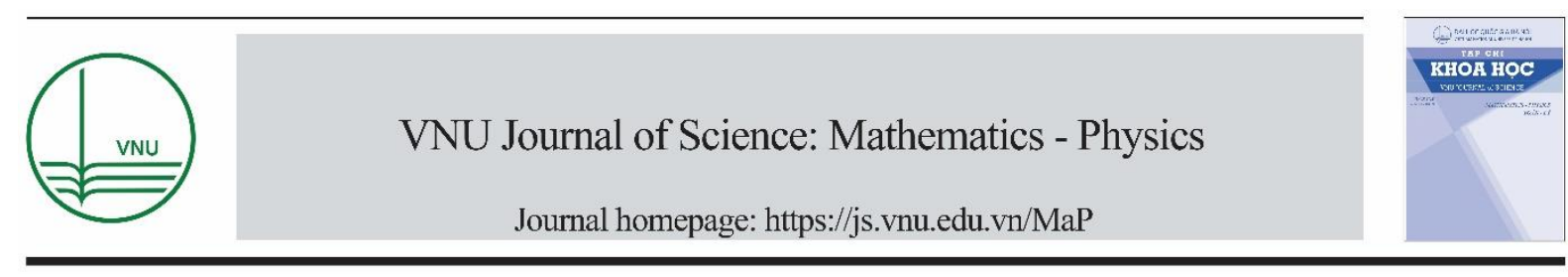

Original Article

\title{
Fabrication of Highly Efficient Pervoskite Solar Cells Using Simple Single-step Solution Method
}

\author{
Quang-Duy Dao* \\ VNU University of Science, 334 Nguyen Trai, Thanh Xuan, Hanoi, Vietnam
}

Received 16 June 2020

Revised 18 August 2020; Accepted 05 September 2020

\begin{abstract}
This article presents optical property, crystal structure, and photovoltaic performance of perovskite solar cell (PSC) in n-i-p structure using simple single-step solution method with antisolvent drip. The fabricated PSC exhibited a relatively high photovoltaic performance with the best power conversion efficiency of $15.8 \%$ under forward bias scan. The relatively high photovoltaic performance was probably resulted from the high crystallization, the high absorption coefficient, and the crack-like void-free on the surface of the perovskite absorbers.

Keywords: Perovskite solar cell, thin film, wet processing, interfacial engineering
\end{abstract}

\section{Introduction}

With recent increase in awareness of environmental issues, green and renewable energy sources including wind, hydro, solar energy have gained considerable attention. In terms of photovoltaic application, perovskite solar cells (PSCs) have been considered as a potential candidate for nextgeneration solar-energy conversion, because of their appealing characteristics, such as broad light absorption throughout visible wavelength region, low-cost of precursors, and long exciton diffusion length [1-5]. The term perovskite refers to the crystal structure of calcium titanate, which discovered by German mineralogist Gustav Rose and named in honor of Russian mineralogist Lev Perovski [6]. Perovskites in the field of optoelectronics are groups of materials with the formula $\mathrm{ABX}_{3}$, where $\mathrm{A}$ is inorganic or organic cation $\left(\mathrm{Cs}^{+}\right.$or $\mathrm{CH}_{3} \mathrm{NH}_{3}{ }^{+}(\mathrm{MA}), \mathrm{NH}_{2} \mathrm{CHNH}_{3}{ }^{+}(\mathrm{FA})$ ), $\mathrm{B}$ is a divalent metal cation $\left(\mathrm{Pb}^{2+}\right.$ or $\left.\mathrm{Sn}^{2+}\right)$, and $\mathrm{X}$ is a monovalent halide anion $\left(\mathrm{I}^{-}, \mathrm{Br}^{-}\right.$, or $\left.\mathrm{Cl}^{-}\right)$[6].

\footnotetext{
${ }^{*}$ Corresponding author.

Email address: daoquangduy@hus.edu.vn
}

https//doi.org/ 10.25073/2588-1124/vnumap.4557 
Although the first PSC with power conversion efficiency (PCE) exceeding 3\% was demonstrated by Myasaka in 2009, the so-called perovskite fever has not fully bloomed until Snaith developed a solidstate cell with PCE exceeding 10\% in 2012 [6-8]. Since then, the photovoltaic performance of PSC has remarkably improved and the high-PCE and stability devices were demonstrated [5]. The rapidly improvement in the photovoltaic performance was resulted from a combination of thin-film perovskite fabrication, device architecture, contact engineering, and interfacial engineering [9-12]. The photovoltaic properties of PSC were strongly dependent on the quality of the perovskite absorber and the highest-PCE PSCs were demonstrated with the high-quality perovskite films, which possess the appropriate morphology, uniformity, phase purity, and crystallinity [5]. To achieve these quality criteria, deposition approach, precursor composition, processing condition, and additive control were taken into account. Focusing on the perovksite deposition approach, the preparation processes could be categorized as follows: single- step solution deposition, two-step solution deposition, two-step vapor-assisted deposition, and thermal vapor deposition [13-16]. It was reported that single-step solution deposition was commonly utilized for perovskite thin film preparation due to ease of processing and low fabrication cost [6]. In this study, we demonstrated the fabrication of high-efficient PSC using simple single-step solution method. Furthermore, the optical properties and crystal structure of the synthesized perovskite films were taken into account.

\section{Experimental Procedure}

\subsection{Sample and Device Fabrication}

The PSC in n-i-p structure had a device architecture as shown in Figure 1(a). The device was fabricated in accordance with the previous literature on an etched fluorine doped tin oxide (FTO) coated glass substrate with the sheet resistance of around $7 \Omega / \mathrm{cm}^{2}[17,18]$. The active area was about $0.24 \mathrm{~cm}^{2}$. Initially, FTO-coated glasses were patterned by wet-etching process, using $2 \mathrm{M} \mathrm{HCl}$ and zinc powder at room temperature. The patterned substrate was then cleaned sequentially by ultrasonic cleaner for 15 min in detergent, water, ethanol and acetone. Before thin-film deposition, the patterned FTO-coated glasses were treated for $30 \mathrm{~min}$ by UV-induced ozone to remove the redundant organic solvents. After that, the compact $\mathrm{TiO}_{2}$ electron transport layer (ETL) was deposited by spraying a solution of $300 \mu \mathrm{L}$ titanium diisopropoxide bis(acetylacetonate) (Aldrich) in $4 \mathrm{~mL}$ of ethanol on the FTO substrates and heated at $500{ }^{\circ} \mathrm{C}$ for $30 \mathrm{~min}$. The thickness of the $\mathrm{TiO}_{2}$ compact layer was around $50 \mathrm{~nm}$. The compact $\mathrm{TiO}_{2}$ ETL was then immersed in an aqueous solution of $\mathrm{TiCl}_{4}$ (Wako) $\left(220 \mu \mathrm{L}\right.$ of $\mathrm{TiCl}_{4}$ mixed with 100 $\mathrm{mL}$ water) at $70{ }^{\circ} \mathrm{C}$ for $20 \mathrm{~min}$, then rinsed with deionized water and sintered at $500{ }^{\circ} \mathrm{C}$ for $30 \mathrm{~min}$. Mesoporous $\mathrm{TiO}_{2}$ (DSL 18NR-T, DYESOL) film was deposited onto the compact $\mathrm{TiO}_{2}$ ETL by spin coating method and treated at $250{ }^{\circ} \mathrm{C}$ for 30 and $500{ }^{\circ} \mathrm{C}$ for $30 \mathrm{~min}$, respectively. The thickness of mesoporous $\mathrm{TiO}_{2}$ film was around $300 \mathrm{~nm}$. The mesoporous $\mathrm{TiO}_{2}$ layers were also treated by immersing in $\mathrm{TiCl}_{4}$ solution as aforementioned. The perovskite absorber was deposited onto the top of fabricated substrates in $\mathrm{N}_{2}$-filled glove-box by spin-coating a mixed precursor solution of methylammonium iodide $\left(\mathrm{CH}_{3} \mathrm{NH}_{3} \mathrm{I}\right.$; Tokyo Chemical Industry Co. $)$ and lead iodide $\left(\mathrm{PbI}_{2}\right.$, Tokyo Chemical Industry Co.) (1:1 molar ratio, final concentrations $1.1 \mathrm{M}$ lead iodide and $1.1 \mathrm{M}$ methylammonium iodide) in dimethylsulphoxide. During spinning process, toluene $(0.5 \mathrm{~mL})$ or Diethyl ether $(0.5 \mathrm{~mL})$ anti-solvents were dripped on the substrates to uniform and dense the perovskite absorber via the $\mathrm{CH}_{3} \mathrm{NH}_{3} \mathrm{I}-\mathrm{PbI}_{2}-\mathrm{DMSO}$ intermediate phases $[19,20]$. The spin coating speed and toluenedropping time are shown in Figure 1(b). The pervoskite absorber thin film was annealed at $120^{\circ} \mathrm{C}$ for 10 min in $\mathrm{N}_{2}$-filled glove-box. Sequence, the poly(triarylamine) (PTAA) hole transport layers (HTLs) were deposited by spin-coating a solution of $10 \mathrm{mg}$ PTAA in $1 \mathrm{~mL}$ toluene. To improve the charge 
carrier mobility of PTAA HTM as well as the photovoltaic performance of PSCs, $1.3 \mathrm{mg}$ of lithium bis (trifluoromethanesulfonyl)imide (LiTFSI, Tokyo chemical industry) and $4 \mu \mathrm{L}$ of 4-tert-butylpyridine (96\%, SigmaAldrich) were introduced to the PTAA solution. The thickness of the PTAA HTL and that of $\mathrm{CH}_{3} \mathrm{NH}_{3} \mathrm{PbI}_{3}$ perovskite layer were approximately 120 and $400 \mathrm{~nm}$, respectively. The fabricated thin film was then annealed at $70{ }^{\circ} \mathrm{C}$ for $10 \mathrm{~min}$ to remove the redundant organic solvents and kept overnight in $\mathrm{N}_{2}$-filled glove-box. Finally, Au films were deposited through a shadow mask by thermal evaporation under a vacuum of about $3 \times 10^{-5}$ Torr. The thickness of Au films was around $80 \mathrm{~nm}$. All used chemicals and solvents were purchased from chemical companies and used as received.

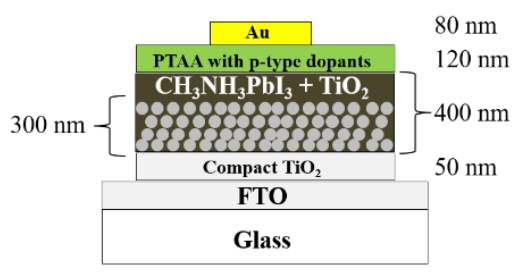

(a)

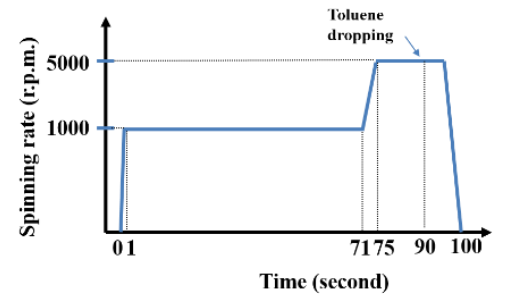

(b)

Figure 1. (a) Device architecture and (b) Spin profile during coating in this study.

\subsection{Film and Device Characterization}

The current density-voltage $(J-V)$ characteristic of the device in this study was estimated using a 6243 DC voltage current source/monitor under illumination of a solar simulator equipped with an AM 1.5 filter (WXS-50S-1.5) at the light intensity of $100 \mathrm{~mW} / \mathrm{cm}^{2}$. The light intensity of solar simulator was calibrated with a mono-crystalline Si solar cell. During the $J-V$ measurement, the aperture with area of around $0.24 \mathrm{~cm}^{2}$ was used and the temperature of device was kept at $25^{\circ} \mathrm{C}$. While the reverse $J-V$ curve was scanned from 1.2 to $-0.1 \mathrm{~V}$ with $0.0065 \mathrm{~V}$ steps, integrating the signal for $0.0167 \mathrm{~s}$, the forward $J$ $V$ curve was scanned from -0.1 to $1.2 \mathrm{~V}$ with $0.026 \mathrm{~V}$ steps, integrating the signal for $1.67 \mathrm{~S}$. The absorbance spectra and X-ray diffraction (XRD) patterns of thin films were measured using spectrophotometry (Shimadzu UV-3150) and an X-ray diffractometer (Rigaku SmartLab), respectively. The thin-film thickness and surface morphology were characterized using surface profilometer (Dektak 150), scanning electron microscopy (SEM; Miniscope TM3000), and atomic force microscopy (AFM; Keyence VN-8000), respectively.

\section{Results and Discussion}

In photovoltaic device, absorption coefficient of absorber, which describes the intensity attenuation of light passing through an absorber, plays a key role. The higher absorption coefficient of absorber is, the higher PCE of photovoltaic device is. The absorption coefficient of $\mathrm{CH}_{3} \mathrm{NH}_{3} \mathrm{PbI}_{3}$ perovskite thin film fabricated on glass substrate using single-step solution method with toluene drip was, thereby, estimated from the absorbance spectra, as shown in Figure 2. The $\mathrm{CH}_{3} \mathrm{NH}_{3} \mathrm{PbI}_{3}$ perovskite thin film had a strong and broad absorption band from 300 to 800, which covers all the visible spectral range with the absorption onset of around $798 \mathrm{~nm}$. Those results are in line with the literatures [21]. It also indicated that the absorption coefficient of the perovskite thin film was relatively high and exceeded $5.2 \times 10^{4} \mathrm{~cm}^{-}$ ${ }^{1}$ at $700 \mathrm{~nm}$, corresponding to the penetration depth of $190 \mathrm{~nm}$. And, the energy band gap of the perovskite thin film, which derived from the absorption onset, was around $1.55 \mathrm{eV}$. 


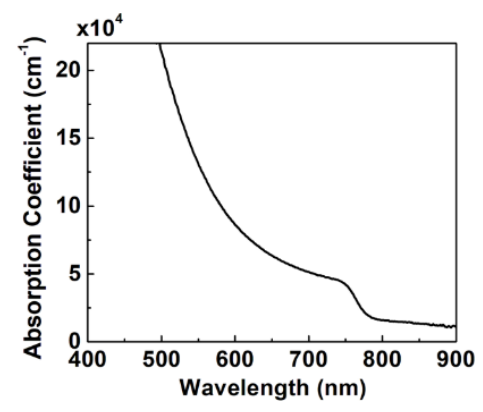

Figure 2. Dependence of optical absorption coefficient of $\mathrm{CH}_{3} \mathrm{NH}_{3} \mathrm{PbI}_{3}$ perovskite layer fabricated by single-step solution method with toluene drip on wavelength.

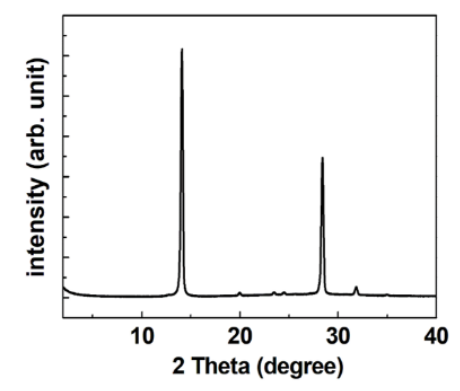

Figure 3. XRD pattern of $\mathrm{CH}_{3} \mathrm{NH}_{3} \mathrm{PbI}_{3}$ perovskite layer fabricated by single-step solution method with toluene drip.

Analysis of the structure of the fabricated perovskite thin films was performed using an X-ray diffractometer. Figure 3 shows the XRD pattern of $\mathrm{CH}_{3} \mathrm{NH}_{3} \mathrm{PbI}_{3}$ perovskite thin film, which was fabricated on glass substrate using single-step solution method with toluene drip. The $\mathrm{CH}_{3} \mathrm{NH}_{3} \mathrm{PbI}_{3}$ perovskite in solid phase exhibited strong diffraction peaks at $14.1^{\circ}, 28.3^{\circ}$ and $31.8^{\circ}$, corresponding to the (110), (220), and (310) crystal planes, respectively [22-24]. Those strong XRD peaks indicated that the perovskite thin films were well crystallized, in part, due to the thermal annealing process and/or the anti-solvent drip. Furthermore, the plane distance (D) and the crystallite sizes (s) of the $\mathrm{CH}_{3} \mathrm{NH}_{3} \mathrm{PbI}_{3}$ perovskite were then estimated using Bragg' law $(n \lambda=2 D \sin \theta)$ and Scherrer formula $(s=K \lambda / \beta \cos \theta)$, respectively. Herein, $\mathrm{K}$ is the shape factor ( 0.9 was used in this study), $\lambda$ is the $\mathrm{x}$-ray wavelength of $1.5418 \AA, \beta$ is full width at half-maximum, and $\theta$ is the Bragg angle. The (110) plane distance and crystallite size were estimated to be around $6.3 \AA$ and $34.1 \mathrm{~nm}$, respectively.

One important factor in designing and fabricating high-efficient and stability PSCs is complete coverage and uniformity of perovskite thin film. Solution-processed perovskite films, however, tend to have voids between the crystals, which are detrimental to device performance [10, 25]. Therefore, the perovskite thin films fabricated on glass substrate using single-step solution method with toluene drip were analyzed using SEM and AFM. Figures 4 shows the top-view SEM image of the fabricated $\mathrm{CH}_{3} \mathrm{NH}_{3} \mathrm{PbI}_{3}$ perovskite thin film. It indicated that the fabricated $\mathrm{CH}_{3} \mathrm{NH}_{3} \mathrm{PbI}_{3}$ perovskite films had the special crystalline features of the halogen organic-inorganic perovskite materials with the grain size of around $3 \mu \mathrm{m}$ and the crack-like void-free between grain boundaries [10,25]. We suggested that the complete coverage and uniformity of the fabricated perovskite films was probably resulted from dripping anti-solvent during spinning [19, 20]. Furthermore, those SEM images were accordant with the 
AFM topography image, as shown in Figure 5. The $\mathrm{CH}_{3} \mathrm{NH}_{3} \mathrm{PbI}_{3}$ perovskite thin films exhibited the large poly domains and the root-mean-square roughness of around $5 \mu \mathrm{m}$ and $49.3 \mathrm{~nm}$, respectively.

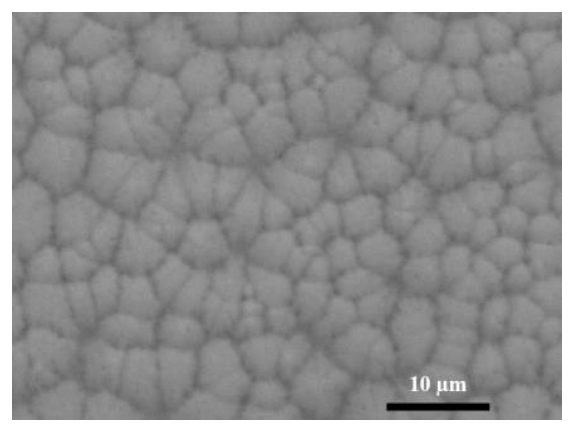

Figure 4. Top-view SEM image of $\mathrm{CH}_{3} \mathrm{NH}_{3} \mathrm{PbI}_{3}$ pervoskite layer fabricated by single-step solution method with toluene drip.

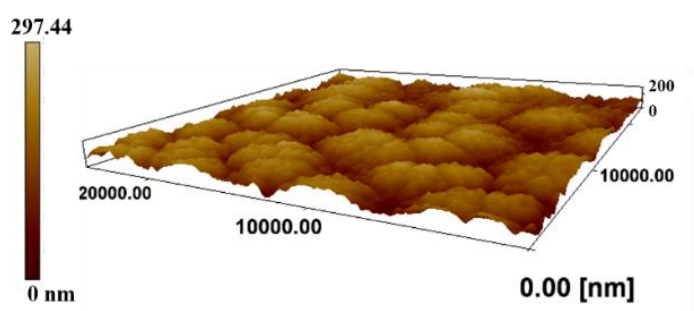

Figure 5. AFM image of $\mathrm{CH}_{3} \mathrm{NH}_{3} \mathrm{PbI}_{3}$ pervoskite layer fabricated by single-step solution method with toluene drip.

Figure 6 shows the $J-V$ characteristic of PSC on glass substrates in $\mathrm{FTO} /$ compact $\mathrm{TiO}_{2} /$ mesoporous $\mathrm{TiO}_{2} / \mathrm{CH}_{3} \mathrm{NH}_{3} \mathrm{PbI}_{3}$ perovskite/PTAA/Au structure, under 1-sun condition (AM $1.5 \mathrm{G}$ illumination with the intensity of $100 \mathrm{~mW} / \mathrm{cm}^{2}$ ). The $\mathrm{CH}_{3} \mathrm{NH}_{3} \mathrm{PbI}_{3}$ perovskite thin films in those devices were fabricated using single-step solution method with toluene or diethyl ether drip. The statistical data of those devices under forward bias scans (from short circuit to forward bias) and reverse bias scans (from forward bias to short circuit) are, furthermore, summarized in Table 1. Under reverse bias scans, the devices fabricated using single-step solution method with toluene drip exhibited the short-circuit current density $\left(J_{\text {sc }}\right)$ of $22.2 \pm 0.4 \mathrm{~mA} / \mathrm{cm}^{2}$ and the open-circuit voltage $\left(V_{\text {oc }}\right)$ of $0.99 \pm 0.02 \mathrm{~V}$. With fill factor $(F F)$ of $0.62 \pm 0.02$, the PCEs of $13.7 \pm 0.5 \%$ were achieved. The relatively high photovoltaic performance of the fabricated device was probably resulted from the high crystallization, the high absorption coefficient, and the crack-like void-free on the surface of the perovskite absorber $[10,25]$. On other hand, the PCE of $15.5 \pm 0.3 \%$ was achieved under forward bias scans. The dependence of the photovoltaic characteristics on the direction of voltage sweep indicated that the fabricated devices had the $J-V$ hysteresis. Although more effort should be made to understand the $J$ - $V$ hysteresis of the devices, we suggested that the $J-V$ hysteresis was probably resulted from the charge transfer rates at the interfaces of the perovskite absorber in the conventional n-i-p structure and/or the phenomena of slow charge trapping and de-trapping in the defects of perovskite absorber [26, 27]. 

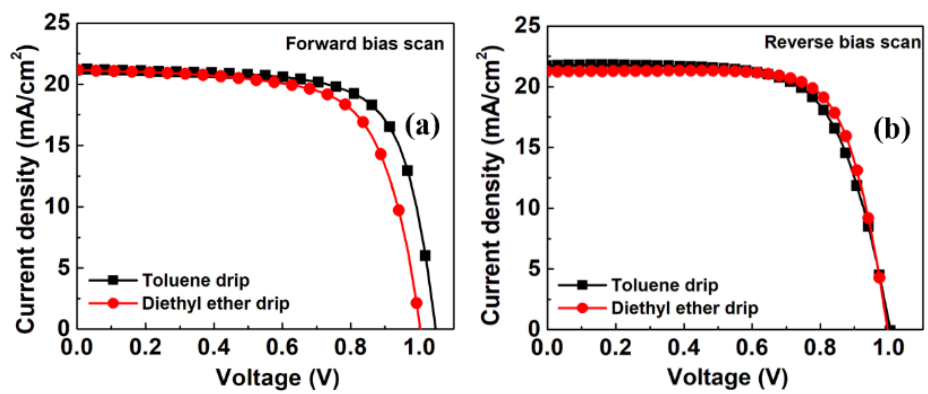

Figure 6. $J$ - $V$ characteristic of PSCs in $\mathrm{FTO} /$ compact $\mathrm{TiO}_{2} /$ mesoporous $^{\mathrm{TiO}_{2}} /$ perovskite/PTAA/Au structure.

Table 1. Cell characteristic of $\mathrm{PSC}$ in $\mathrm{FTO} /$ compact $\mathrm{TiO}_{2} /$ mesoporous $\mathrm{TiO}_{2} /$ perovskite/PTAA/Au structure; Error values represent the standard deviation of the mean of 6 devices.

\begin{tabular}{|l|l|l|l|l|l|l|}
\hline \multicolumn{2}{|l|}{ Dripping solvent } & $V_{\text {oc }}(\mathrm{V})$ & $\begin{array}{l}J_{\text {sc }} \\
\left(\mathrm{mA} / \mathrm{cm}^{2}\right)\end{array}$ & $F F$ & $P C E(\%)$ & $\begin{array}{l}\text { Best } \\
(\%)\end{array}$ \\
\hline \multirow{2}{*}{ Toluene } & Forward & $1.04 \pm 0.01$ & $21.5 \pm 0.3$ & $0.69 \pm 0.01$ & $15.5 \pm 0.3$ & 15.8 \\
\cline { 2 - 8 } & Reverse & $0.99 \pm 0.02$ & $22.2 \pm 0.4$ & $0.62 \pm 0.02$ & $13.7 \pm 0.5$ & 14.9 \\
\hline \multirow{2}{*}{ Diethyl ether } & Forward & $0.99 \pm 0.01$ & $20.6 \pm 0.4$ & $0.65 \pm 0.01$ & $13.2 \pm 0.7$ & 14.4 \\
\cline { 2 - 8 } & Reverse & $0.99 \pm 0.02$ & $20.6 \pm 0.7$ & $0.70 \pm 0.01$ & $14.4 \pm 0.8$ & 15.5 \\
\hline
\end{tabular}

The devices fabricated using single-step solution method with diethyl ether drip, otherwise, exhibited the relatively high photovoltaic performance with the PCE of $14.4 \pm 0.8 \%$ under reverse bias scans. The high PCE of the PSC using diethyl ether drip was mainly resulted from the high $F F$. However, the PCE under forward bias scans of the devices using diethyl ether drip was reduced to $13.2 \pm 0.7 \%$. Although, more efforts should be made to understand the dependence of the device photovoltaic performance on the anti-solvent drip, we suggested that the boiling point of the anti-solvents and solubility of the $\mathrm{CH}_{3} \mathrm{NH}_{3} \mathrm{PbI}_{3}$ perovskite components in the anti-solvents affected the crystallization and the morphology of the perovskite thin films as well the device photovoltaic performance.

\section{Conclusion}

In summary, we reported on the optical properties, crystal structure, and photovoltaic performance of PSCs in FTO/compact $\mathrm{TiO}_{2} /$ mesoporous $\mathrm{TiO}_{2} / \mathrm{CH}_{3} \mathrm{NH}_{3} \mathrm{PbI}_{3}$ perovskite/PTAA/Au structure using simple single-step solution method with toluene or diethyl ether drip. The perovskite thin films absorbed all the light in visible spectral range with the high absorption coefficient and exhibited the unique crystalline features of the halogen organic-inorganic perovskite materials with the length scale in the order of several micrometers and crack-like void-free between crystal boundaries. As a result, the device fabricated using simple single-step solution method with toluene drip possessed the relatively high photovoltaic performance with the best PCE of $15.8 \%$ under forward bias scans.

\section{Acknowledgments}

This research is funded by Vietnam National Foundation for Science and Technology Development (NAFOSTED) under Grant 103.02-2018.320. The author also thanks Dr. Hung Nguyen (VNU- 
University of Science), Prof. Ryotaro Tsuji (Kaneka Corporation, Japan), Prof. Akihiko Fujii (Osaka University, Japan), and Prof. Masanori Ozaki (Osaka University, Japan) for their material and equipment supports.

\section{References}

[1] G. Xing, N. Mathews, S. Sun, S. S. Lim, Y. M. Lam, M. Grätzel, S. Mhaisalkar, T. C. Sum, Long-Range Balanced Electronand Hole-Transport Lengths in Organic-Inorganic $\mathrm{CH}_{3} \mathrm{NH}_{3} \mathrm{PbI}_{3}$, Science, Vol. 342, No. 6156, 2013, pp. 344-347. DOI: 10.1126/science.1243167.

[2] S. D. Stranks, G. E. Eperon, G. Grancini, C. Menelaou, M. J. P. Alcocer, T. Leijtens, L. M. Herz, A. Petrozza, H. J. Snaith, Electron-Hole Diffusion Lengths Exceeding 1 Micrometer in an Organometal Trihalide Perovskite Absorber, Science, Vol. 342, No. 6156, 2013, pp. 341-344. DOI: 10.1126/science.1243982.

[3] H. S. Jung, N.-G. Park, Perovskite Solar Cells: From Materials to Devices, small, Vol. 11, No. 1, 2015, pp. 10-25. https://doi.org/10.1002/smll.201402767.

[4] G. Niu, X. Guo, L. Wang, Review of Recent Progress in Chemical Stability of Perovskite Solar Cells, J. Mater. Chem. A, Vol. 3, No. 17, 2015, pp. 8970-8980. https://doi.org/10.1039/C4TA04994B.

[5] M. A. Green, Y. Hishikawa, E. D. Dunlop, D. H. Levi, J. H. Ebinger, M. Yoshita, A. W.Y. Ho-Baillie, Solar Cell Efficiency Tables (Version 53), Prog. Photovolt. Res. Appl., Vol. 27, No. 1, 2019, pp. 3-12. https://doi.org/10.1002/pip.3102.

[6] Z. Song, S. C. Watthage, A. B. Phillips, M. J. Heben, Pathways Toward High Performance Perovskite Solar Cells: Review of Recent Advances in Organo-metal Halide Perovskites for Photovoltaic Applications, J. Photon. Energy, Vol. 6, No. 2, 2016, pp. 022001-1-022001-23. DOI: 10.1117/1.JPE.6.022001.

[7] A. Kojima, K. Teshima, Y. Shirai, T. Miyasaka, Organometal Halide Perovskites as Visible-Light Sensitizers for Photovoltaic Cells, J. Am. Chem. Soc., Vol. 131, No. 17, 2009, pp. 6050-6051. https://doi.org/10.1021/ja809598r.

[8] M. M. Lee, J. Teuscher, T. Miyasaka, T. N. Murakami, H. J. Snaith, Efficient Hybrid Solar Cells Based on MesoSuperstructured Organometal Halide Perovskites, Science, Vol. 338, No. 6107, 2012, pp. 643-647. https://10.1126/science.1228604.

[9] H. B. Kim, H. Choi, J. Jeong, S. Kim, B. Walker, S. Song, J. Y. Kim, Mixed Solvents for the Optimization of Morphology in Solution-Processed, Inverted-Type Perovskite/Fullerene Hybrid Solar Cells, Nanoscale, Vol. 6, No. 12, 2014, pp. 6679-6683. https://doi.org/10.1039/C4NR00130C

[10] Q. D. Dao, R. Tsuji, A. Fujii, M. Ozaki, Study on Degradation Mechanism of Perovskite Solar Cell and Their Recovering Effects by Introducing $\mathrm{CH}_{3} \mathrm{NH}_{3} \mathrm{I}$ Layers, Org. Electron., Vol. 43, No. 43, 2017, pp. 229-234. https://doi.org/10.1016/j.orgel.2017.01.038.

[11] H. Wang, X. Hu, H. Chen, The Effect of Carbon Black in Carbon Counter Electrode for $\mathrm{CH}_{3} \mathrm{NH}_{3} \mathrm{PbI}_{3} / \mathrm{TiO}_{2}$ Heterojunction Solar Cells, RSC Adv., Vol. 5, No. 38, 2015, pp. 30192-30196. https://doi.org/10.1039/C5RA02325D.

[12] H. Zhou, Q. Chen, G. Li, S. Luo, T.-B. Song, H.-S. Duan, Z. Hong, J. You, Y. Liu, Y. Yang, Interface Engineering of Highly Efficient Perovskite Solar Cells, Science, Vol. 345, No. 6196, 2014, pp. 542-546. https://10.1126/science.1254050.

[13] T. H. Le, Q. D. Dao, M.-P. Nghiem, S. Peralta, R. Guillot, Q. N. Pham, A. Fujii, M. Ozaki, F. Goubard, T.-T. Bui, Triphenylamine-Thienothiophene Organic Charge-Transport Molecular Materials: Effect of Substitution Pattern on Their Thermal, Photoelectrochemical, and Photovoltaic Properties, Chem. Asian J., Vol. 13, No. 10, 2018, pp. 1302-1311. https://doi.org/10.1002/asia.201701790

[14] J. Burschka, N. Pellet, S.-J. Moon, R. H. Baker, P. Gao, M. K. Nazeeruddin, M. Grätzel, Sequential Deposition as a Route to High-Performance Perovskite-Sensitized Solar Cells, Nature, Vol. 499, No. 7458, 2013, pp. 316-319. https://10.1038/nature12340.

[15] M. Liu, M. B. Johnston, H. J. Snaith, Efficient Planar Heterojunction Perovskite Solar Cells by Vapour Deposition, Nature, Vol. 501, No. 7467, 2013, pp. 395-398. https://doi.org/10.1038/nature12509. 
[16] Q. Chen, H. Zhou, Z. Hong, S. Luo, H. S. Duan, H. H. Wang, Y. Liu, G. Li, Y. Yang, Planar Heterojunction Perovskite Solar Cells via Vapor-Assisted Solution Process, J. Am. Chem. Soc., Vol. 136, No. 2, 2014, pp. 622625. https://doi.org/10.1021/ja411509g.

[17] Q. D. Dao, A. Fujii, R. Tsuji, M. Ozaki, A study on Solution-Processable Tetrabenzomonoazaporphyrin Hole Transport Material for Pervoskite Solar Cells, Adv. Nat. Sci.: Nanosci. Nanotechnol., Vol. 11, No. 1, 2020, pp. 015007-1-015007-6. https://doi.org/10.1088/2043-6254/ab6c4d.

[18] Q. D. Dao, A. Fujii, R. Tsuji, M. Ozaki, Highly Efficient Perovskite Solar Cell Utilizing a Solution-Processable Tetrabenzoporphyrin Hole Transport Material with p-type Dopants, Appl. Phys. Express, Vol. 12, No. 11, 2019, pp. 112009-1-112009-4. https://doi.org/10.7567/1882-0786/ab4aa2.

[19] N. J. Jeon, J. H. Noh, Y. C. Kim,W. S. Yang, S. Ryu, S. I. Seok, Solvent Engineering for High-Performance Inorganic-Organic Hybrid Perovskite Solar Cells, Nat. Mater., Vol. 13, No. 9, 2014, pp. 897-903. DOI: $10.1038 /$ nmat4014.

[20] G. E. Eperon, V. M. Burlakov, P. Docampo, A. Goriely, H. J. Snaith, Morphological Control for High Performance, Solution Processed Planar Heterojunction Perovskite Solar Cells, Adv. Funct. Mater., Vol. 24, No. 1, 2014, pp. 151-157. https://doi.org/10.1002/adfm.201302090.

[21] Y. Li, W. Yan, Y. Li, S. Wang, W. Wang, Z. Bian, L. Xiao, Q. Gong, Direct Observation of Long Electron-Hole Diffusion Distance in $\mathrm{CH}_{3} \mathrm{NH}_{3} \mathrm{PbI}_{3}$ Perovskite Thin Film, Sci. Rep., Vol. 5, No. 1, 2015, pp. 144851-14485-7. https://doi.org/10.1038/srep14485.

[22] S. Kavadiya, J. Strzalka, D. M. Niedzwiedzki, P. Biswas, Crystal Reorientation in Methylammonium Lead Iodide Perovskite Thin Film with Thermal Annealing, J. Mater. Chem. A, Vol. 7, No. 20, 2019, pp. 12790-12799. https://doi.org/10.1039/C9TA02358E.

[23] L. M. Chao, T. Y. Tai, Y. Y. Chen, P. Y. Lin, Y. S. Fu, Fabrication of $\mathrm{CH}_{3} \mathrm{NH}_{3} \mathrm{PbI}_{3} / \mathrm{PVP}$ Composite Fibers via Electro Spinning and Deposition, Materials, Vol. 8, No. 8, 2015, pp. 5467-5478. https://doi.org/10.3390/ma8085256.

[24] H. Zhou, Q. Chen, G. Li, S. Luo, T. B. Song, H. S. Duan, Z. Hong, J. You, Y. Liu, Y. Yang, Interface Engineering of Highly Efficient Perovskite Solar Cells, Science, Vol. 345, No. 6196, 2014, pp. 542-546. https://10.1126/science.1254050.

[25] J. Y. Jeng, Y. F. Chiang, M. H. Lee, S. R. Peng, T. F. Guo, P. Chen, T. C. Wen, $\mathrm{CH}_{3} \mathrm{NH}_{3} \mathrm{PbI}_{3}$ Perovskite Fullerene Planar Heterojunction Hybrid Solar Cells, Adv. Mater., Vol. 25, No. 27, 2013, pp. 3727-3732. https://doi.org/10.1002/adma.201301327.

[26] S. H. Kim, D. Lee, Role of Charge Trapping Iodine Frenkel Defects for Hysteresis in Organic-Inorganic Hybrid Perovskite From First-Principles Calculations, J. Phys. Chem. C, Vol. 123, No. 14, 2019, pp. 9629-9633. https://doi.org/10.1021/acs.jpcc.9b01770.

[27] B. Chen, M. Yang, S. Priya, K. Zhu, Origin of J-V Hysteresis in Perovskite Solar Cells, J. Phys. Chem. Lett., Vol. 7, No. 5, 2016, pp. 905-917. https://doi.org/10.1021/acs.jpclett.6b00215. 